\title{
Pancreatic Focal Lesion Mimicking Carcinoma in Association with Ulcerative Colitis
}

\author{
Hind I. Fallatah, МВСн \\ Department of Medicine, Faculty of Medicine \\ King Abdulaziz University, Jeddah, Saudi Arabia \\ hindfallatah@hotmail.com
}

\begin{abstract}
A patient with ulcerative colitis presented with jaundice and bloody diarrhea. He had cholestatic derangement of liver enzymes with radiological features of focal pancreatic mass. He responded completely to Prednisolone and remains asymptomatic on oral Mesalamine.
\end{abstract}

Keywords: Pancreatic focal lesion, Ulcerative colitis.

\section{Introduction}

Extra intestinal manifestations of inflammatory bowel disease are common but pancreatic involvement is rare. The pancreas may be involved as a complication of gallstones or due to duodenal involvement as in Crohn's disease ${ }^{[1]}$. Side effects of such treatment as 5-amino salicylic acid compounds, Azathioprine and steroids on the pancreas was reported $^{[1]}$. In patients with primary sclerosing cholangitis (PSC) complicating inflammatory bowel disease, the pancreas may be involved as part of extra hepatic biliary system involvement or in the form of lymphoplasmacytic sclerosing pancreatitis, a rare variant of PSC involving the pancreas ${ }^{[2]}$. Autoimmune chronic pancreatitis (AIP) and pancreatic masses in association with PSC are well recognized with established diagnostic laboratory and imaging criteria ${ }^{[3,4]}$.

\footnotetext{
Correspondence \& reprint request to: Dr. Hind I. Fallatah

P.O. Box 9714, Jeddah 21423, Saudi Arabia

Accepted for publication: 24 June 2008. Received: 23 February 2008.
} 


\section{Case Report}

A 44-years-old male presented to the Emergency Department on October 7, 2003, with a history of progressively increasing epigastric abdominal pain and jaundice of one-week duration associated with poor appetite and a one-day history of fever, nausea and vomiting. This was preceded by bloody diarrhea for 20 days. He lost $20 \mathrm{~kg}$ of weight over the three weeks.

There was no history of ethanol intake or previous similar attacks. He was diabetic for 3 years on oral hypoglycemic (Glibenclamide).

On physical examination he was ill, in pain, febrile $38.7^{\circ} \mathrm{C}$, pulse 109/minute, BP 119/67 mmHg, mildly pale, and jaundiced. Chest and cardiovascular system were unremarkable. Abdominal examination revealed right upper quadrant and epigastric tenderness. Complete blood count white blood cells (WBC) $13.8 \mathrm{~K} / \mathrm{uL}$ hemoglobin $(\mathrm{Hb})$ was 9.4 $\mathrm{g} / \mathrm{dL}$, platelets count $611 \mathrm{~K} / \mathrm{uL}$. Prothrombin time 1 second, Erythrocyte Sedimentation rate (ESR) was 53 in the first hour. Sodium $131 \mathrm{mmol} / \mathrm{L}$, Potassium $3.1 \mathrm{mmol} / \mathrm{L}$, Chloride $94 \mathrm{mmol} / \mathrm{L}$, urea and creatinine were normal $2.9 \mathrm{mmol} / \mathrm{L}$ and $85 \mathrm{mmol} / \mathrm{L}$, respectively. Random blood sugar was high $17.5 \mathrm{mmol} / \mathrm{L}$. Aspartate Amino Transferase (AST) $180 \mathrm{IU} / \mathrm{L}$, Alanine Amino Transferase (ALT) 110 IU/L, Alkaline phosphatase (ALKP) $733 \mathrm{U} / \mathrm{L}$, Gamma glutamyl transferase (GGT) $666 \mathrm{U} / \mathrm{L}$. The total bilirubin was high $14 \mu \mathrm{mol} / \mathrm{L}$, Direct Bilirubin $140 \mu \mathrm{mol} / \mathrm{L}$, Albumin 22. Hepatitis serology was negative for Hepatitis B Virus (HBV), Hepatitis C Virus (HCV), and Hepatitis A Virus (HAV). Anti nuclear Antibody (ANA), Smooth Muscle Antibody (SMA) and Antimitochondrial Antibody (AMA) were also negative, Immunoglobulin $\mathrm{G}$ ( $\mathrm{IgG}$ ) level was 12 (normal). Carbohydrate antigen 19-9 (CA19-9) was 1.79 (normal), stool was positive for occult blood. Ultrasound abdomen showed dilatation of intra- and extra-hepatic biliary radicle and a hypoechoic focal lesion at the region of the head of the pancreas about $5.2 \times 6 \mathrm{~cm}$ in diameter. Abdominal Computed Tomography (CT) scan showed moderate dilatation of intra- and extrahepatic biliary radicle and enlarged pancreatic head with $4.7 \times 3.3$. Focal lesion was seen at the head of the pancreas which could represent cancer of the pancreatic head or inflammatory mass (Fig. 1).

Endoscopic Retrograde Cholangiography (ERCP) was unsuccessful. 


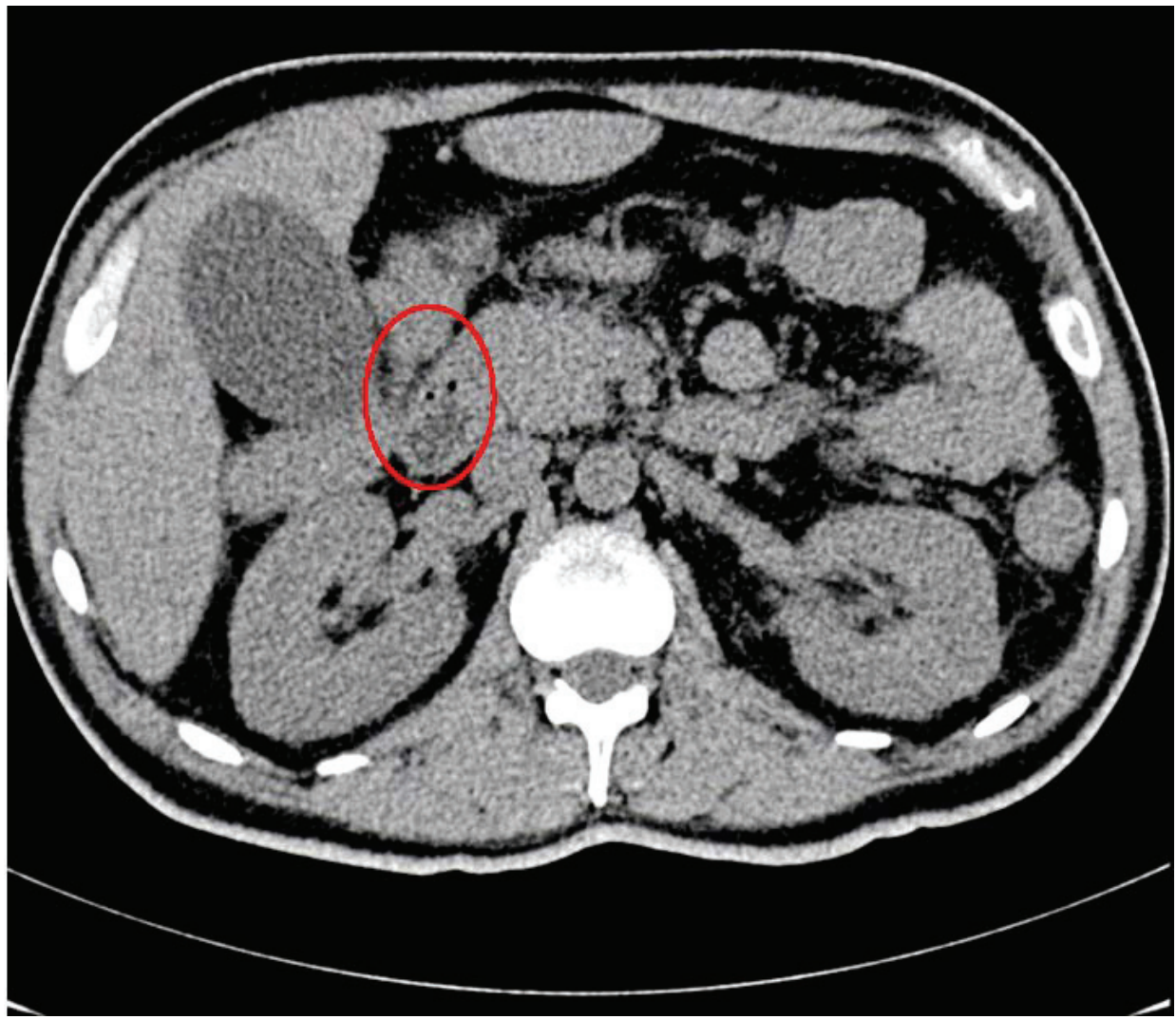

Fig. 1. CT picture of the pancreas: Enlarged head of the pancreas $4.7 \times 3.3$. Focal lesion is seen at the head of the pancreas it could represent cancer of the pancreatic head or inflammatory mass.

Magnetic Resonant Cholangiopancreatography (MRCP) showed dilatation of the intrahepatic biliary radicle, the proximal part of the common bile duct and focal pancreatic head lesion (Fig. 2 to 4). Colonoscopy showed moderate to severe pan-colitis with loss of vascular pattern, friable edematous mucosa and exudate formation. Colonic biopsy showed infiltration of the lamina propria with acute and chronic inflammatory cells and eosinophils with cryptitis. No crypt abscess or granuloma formation (Picture of chronic active colitis consistent with ulcerative colitis).

The patient was started on Prednisolone $30 \mathrm{mg}$ orally and Mesalamine $800 \mathrm{mg}$ three times daily (TID). He made dramatic improvement, fever subsided, jaundice disappeared, and the pain was 
completely relieved. Liver enzymes on October 11, 2003 were AST 17 IU/L and ALT 45 IU/L, ALKP 373 U/L, GGT 240. Tbil 24 UMOL/L Direct Bilirubin $20 \mathrm{UMOL} / \mathrm{L}$. Follow-up CT scan and MRCP after 10 days showed interval decrease in the size of pancreatic head mass and decrease in the extent of the biliary radicle dilatation. He was discharged from the hospital on tapered Prednisolone and Mesalamine. He was seen four weeks later in the outpatient clinic; the liver functions and repeated MRCP were normal. At the latest follow-up in December 2007, he was maintained on Mesalamine $800 \mathrm{mg}$ TID and he was free of symptoms.

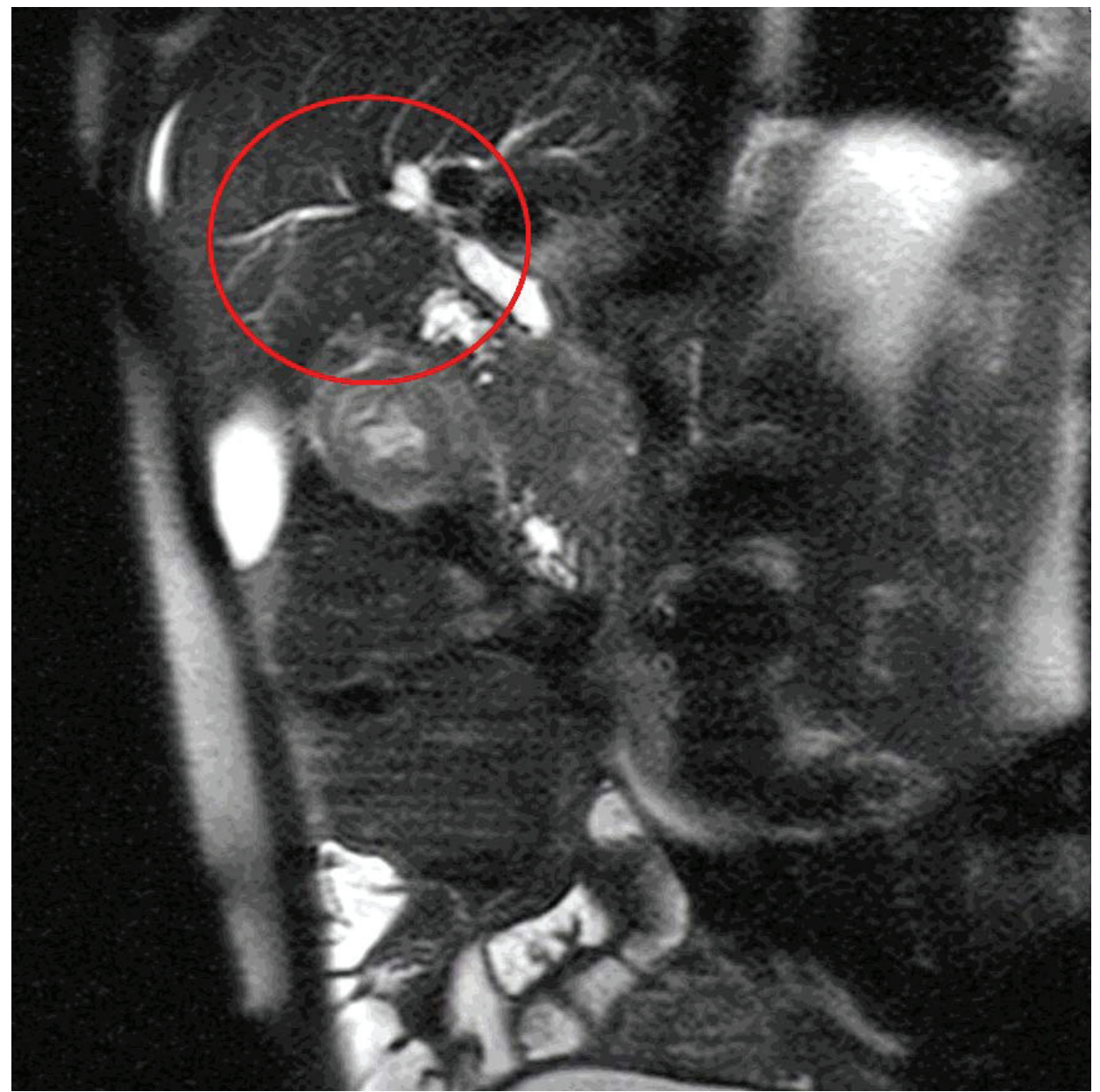

Fig. 2. Dilated intrahepatic biliary radicle and the proximal part of the common bile duct. The distal part is not seen. Focal pancreatic head lesion (MRCP picture 1). 


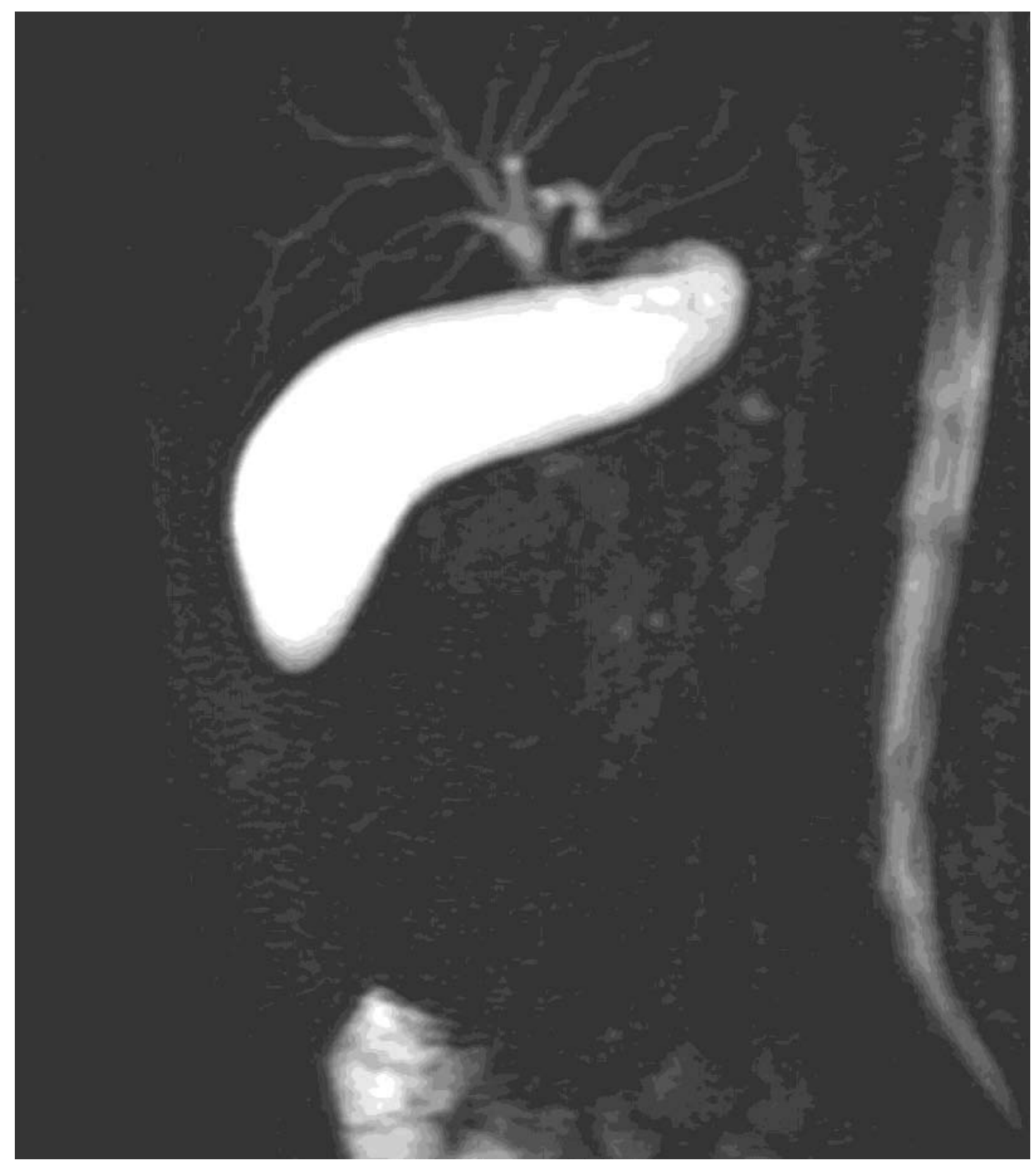

Fig. 3. Dilated biliary system and marked distension of the gallbladder (MRCP picture 2).

\section{Discussion}

Pancreatic involvement such as extra intestinal manifestation in IBD is rare. It may be part of hepatobiliary complications of $\mathrm{IBD}^{[1]}$. It has immunological backgrounds; the so-called autoimmune pancreatitis (AIP). The pathogenesis and pathophysiology of AIP were unclear; 
findings in most cases of AIP included increased levels of serum gamma globulin IgG 4, the presence of autoantibodies, diffuse enlargement of the pancreas, diffusely irregular narrowing of the main pancreatic duct on endoscopic retrograde cholangio-pancreatography, fibrotic changes with lymphocyte infiltration and a possible association with other autoimmune diseases $^{[2]}$. Microscopically AIP is recognized by lymphoplasmacytic sclerosing pancreatitis ${ }^{[2]}$. Similar to the above reported case AIP predominantly tends o affect middle or advanced age males $\mathrm{t}^{\left[\mathrm{t}^{2-4]}\right.}$.

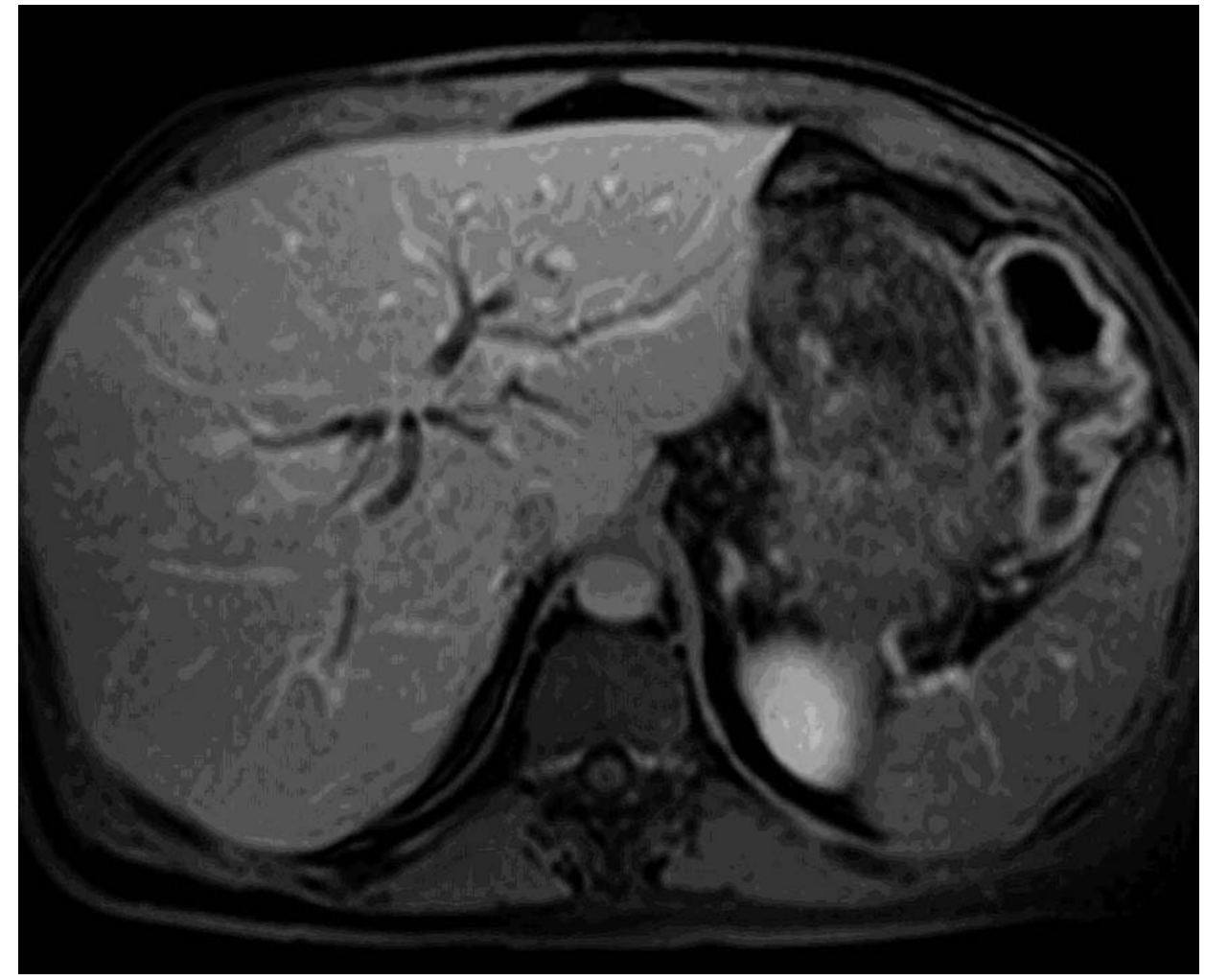

Fig. 4. Intrahepatic biliary radicle. Moderate dilatation (MRCP picture 3).

This patient had acute epigastric pain, fever and vomiting this presentation mimicking acute pancreatitis. Unfortunately, the serum amylase was not done on admission because of the overlapping presentation of bloody diarrhea, which raises the possibility of inflammatory bowel disease or infective colitis. Reports on similar cases of acute pancreatitis associated with ulcerative colitis showed complete response to treatment of the acute attack with systemic steroids ${ }^{[4-6]}$. 
The presence of focal lesion at the head of the pancreas associated with biliary dilatation on abdominal CT scan and MRI associated with jaundice and weight loss raises the possibility of pancreatic cancer. This possibility was supported by failure of cannulation of the common bile duct during the ERCP. Similar cases have been reported with chronic rather than acute presentations ${ }^{[7,8]}$. Some cases in the literature underwent extensive pancreatic surgery for possible carcinoma ${ }^{[7,9]}$. On the other hand the acute presentation of the patient suggested that the pancreatic head focal lesion was more likely of inflammatory origin.

On follow-up for four years the patient was maintained on oral Mesalamine. During this period he had only a few moderate attacks of exacerbation of ulcerative colitis, but without pancreatic involvement.

Sáez et al. ${ }^{[10]}$ reported a similar case of recurrent pancreatitis, which improved without further attacks for 6 years on maintenance 5-ASA.

Autoimmune chronic pancreatitis tends to develop in patients with severe pancolitis. Serum amylase was not found to be as suitably sensitive marker in such patients ${ }^{[11]}$.

Cases of severe chronic pancreatitis with endocrine deficiency have been also reported ${ }^{[12]}$.

\section{Conclusion}

Though AIP is rare, it should be kept in mind as a possible diagnosis in young patients presenting with focal pancreatic lesion especially in patients with inflammatory bowel disease. Elevated serum IgG4 may help in the diagnosis. CT and MRI may not be enough to diagnose pancreatic carcinoma and fine needle aspiration or biopsy is required before subjecting the patient to extensive pancreatic surgery.

\section{References}

[1] Le Large-Guiheneuf C, Hugot JP, Faure C, Munck A, Mougenot J, Navarro J. Pancreatic involvement in inflammatory bowel disease in children. Arch Pediatr 2002; 9(5): 469-477.

[2] Okazaki, K. Autoimmune Pancreatitis. Etiology, Pathogenesis, Clinical findings and treatment the Japanese Experience. JOP: J Pancreas 2005; 6(1 Suppl): 89-96.

[3] Kim KP, Kim MH, Kim JC, Lee SS, Seo DW, Lee SK. Diagnostic criteria for autoimmune chronic pancreatitis revisited. World J Gastroenterol 2006; 12(16): 24872496. 
[4] Tetsuo H, Masaru K, Yutaka A, Kazuichi O, Terumi K, Shigeyuki K, Koichi S, Fumitake T, Isao N. [Diagnostic criteria for autoimmune pancreatitis by the Japan Pancreas Society] J Jpn Pancreas Soc 2002; 17(6): 585-587. Japanese. abstract only.

[5] Kanaji S, Okuma K, Tokumitsu Y, Yoshizawa S, Nakamura M, Niho Y. Hemophagocytic syndrome associated with fulminant ulcerative colitis and presumed acute pancreatitis. Am J Gastroenterol 1998; 93(10): 1956-1959.

[6] Nizam R, Ahmed R, DiMarco AT. Initial presentation of ulcerative colitis with acute pancreatitis. Am J Gastroenterol 2000; 95(3): 825-826.

[7] Okano A, Hajiro K, Takakuwa H, Nishio A. Pseudotumorous pancreatitis associated with ulcerative colitis. Intern Med 2001; 40(12): 1205-1208.

[8] Grandval P, Barthet M, Garcia S, Boustiere C, Poilroux I, Grimaud J. Pseudotumorous chronic pancreatitis associated with inflammatory bowel disease. Dig Dis Sci 2001; 46(4): 898-900.

[9] Lammer J, Herlinger H, Zalaudek G, Hofler H. Pseudotumorous pancreatitis. Gastrointest Radiol 1985; 10(1): 59-67.

[10] Sáez J, Matinez J, Garcia C, Grino P, Mateo M. Idiopathic pancreatitis associated with ulcerative colitis. Am J Gastroenterol 2000; 95(10): 3004-3005.

[11] Barthet M, Hastier P, Bernard JP, Bordes G, Frederick J, Allio S, Mambrini P, SaintPaul MC, Delmont JP, Salducci J, Grimaud JC, Sahel J. Chronic pancreatitis and inflammatory bowel disease true or coincidental association. Am J Gastroenterol 2004; 94(8): 2141-2148.

[12] Kini D, Aggarwal R, Saraswat VA, Naik SR. Symptomatic chronic calcific Pancreatitis in a patient with idiopathic ulcerative colitis and sclerosing cholangitis. Indian $J$ Gastroenterol 2000; 19(1): 29-39. 


\section{آفة بؤرية في البنكرياس مصاحبة لالتهاب القولون التقرحي تمانل سرطان البنكرياس}

\section{هند إبراهيم فلاتة}

قسم التنشريح، كلية الطب، جامعة الملك عبدالعزيز

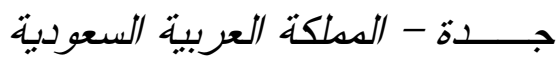

العستخلص. ملخص الحالة أن رجلاً في منوسط العمر أصيب بنوبة

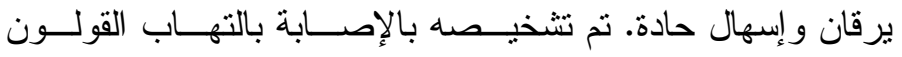

التقرحي، وجد لديه يرقان ركودي، و أظهرت الفحوصات الإشعاعية

وجود آفة بؤرية في البنكرياس ، خضع المريض للعلاج بالستيرويد

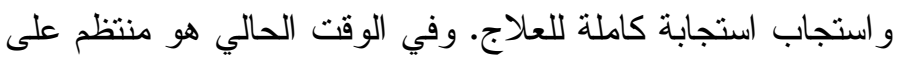

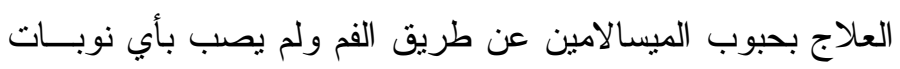

جديدة من تأثز البنكرياس. 